\title{
An Alternative Application to the Portuguese Agro-Industrial Residue: Wheat Straw
}

\author{
Denise S. Ruzene • Daniel P. Silva • António A. Vicente • \\ Adilson R. Gonçalves • José A. Teixeira
}

Received: 9 May 2007 / Accepted: 26 September 2007 /

Published online: 17 October 2007

(C) Humana Press Inc. 2007

\begin{abstract}
The effects of alkaline treatments of the wheat straw with sodium hydroxide were investigated. The optimal condition for extraction of hemicelluloses was found to be with $0.50 \mathrm{~mol} / 1$ sodium hydroxide at $55{ }^{\circ} \mathrm{C}$ for $2 \mathrm{~h}$. This resulted in the release of $17.3 \%$ of hemicellulose ( $\%$ dry starting material), corresponding to the dissolution of $49.3 \%$ of the original hemicellulose. The yields were determined by gravimetric analysis and expressed as a proportion of the starting material. Chemical composition and physico-chemical properties of the samples of hemicelluloses were elucidated by a combination of sugar analyses, Fourier transform infrared (FTIR), and thermal analysis. The results showed that the treatments were very effective on the extraction of hemicelluloses from wheat straw and that the extraction intensity (expressed in terms of alkali concentration) had a great influence on the yield and chemical features of the hemicelluloses. The FTIR analysis revealed typical signal pattern for the hemicellulosic fraction in the $1,200-1,000 \mathrm{~cm}^{-1}$ region. Bands between 1,166 and 1,000 $\mathrm{cm}^{-1}$ are typical of xylans.
\end{abstract}

Keywords Agro-industrial residue - Lignocellulosic materials · Wheat straw - Extraction · Hemicellulose $\cdot$ Papermaking

\section{Introduction}

Agro-industrial residues are renewable, costless, and widespread sources of chemicals. In recent years, there has been an increasing trend towards more efficient utilization of agro-industrial residues such as sugarcane bagasse, cereal straws, corn cob, brewer's spent grain, etc. Advances in industrial biotechnology offer actually potential opportunities for economic utilization of

D. S. Ruzene $(\bowtie) \cdot$ D. P. Silva $\cdot$ A. A. Vicente $\cdot$ J. A. Teixeira

Institute for Biotechnology and Bioengineering, Centre of Biological Engineering, University of Minho, Campus de Gualtar, 4710-057 Braga, Portugal

e-mail: druzene@deb.uminho.pt

\section{A. R. Gonçalves}

Biotechnology Department, Engineering School of Lorena, University of São Paulo, P.O. Box 116, 12602-810 Lorena, São Paulo, Brazil 
agro-industrial residues. Even if in most cases some of these materials are already used, e.g. burned (an application with low added value causing some environmental impact), the lignocellulosic nature and abundant availability make them an ideal substrate for chemical and/ or microbial processes to obtain end products with high added value [1].

The agro-industrial residues are lignocellulosic materials constituted basically of cellulose, hemicelluloses, and lignin. Since society and the industries as a whole have a great interest in the integral use of agro-industrial residues, separation and extraction processes of the structural fractions of lignocellulosic materials are indispensable biotechnological processes for future and successful industrial applications. Currently overproduced and underutilized, the use of these materials is required to accomplish two main objectives: (a) reducing the existence of environmentally hazardous situations and (b) increasing the supply of energy or chemicals produced from renewable resources. Moreover, it is already well known that the cost of this raw material per unit of product can be reduced when all the components of the biomass are converted to added-value products $[2,3]$.

In many countries, the wheat straw is an abundant by-product from wheat production. Thus, wheat straw has potential to serve as a low-cost raw material for production of higher-value industrial products. Wheat straw is an agricultural by-product that is not used as industrial raw material at a significant scale in developed regions like Europe and North America. As a rough estimation, more than 170 million tons of wheat straw are produced yearly in Europe [4]. These amounts are enough to consider wheat straw as a source of renewable materials, particularly for the production of chemical derivatives from cellulose, hemicelluloses, and lignin.

Chemically, about $35-55 \%$ of the dry material is the glucose polymer cellulose, much of which is in a crystalline structure; while another $25-35 \%$ is hemicellulose, an amorphous polymer. The remainder is mostly lignin plus less amounts of minerals, waxes, and other compounds [3]. Cellulose is formed by beta-[1, 4] glucosyl linkages in a linear backbone, whereas hemicelluloses are branched polymers composed of several monosaccharides [5]. Fig. 1 shows the schematic illustration of the cellulose chain, while Fig. 2 shows the schematic illustration of xylans from Gramineae [5, 6].

Research has been done on the separation and structural characterization of the components. Alkali treatment of lignocellulosic substances such as wheat straw disrupts the cell wall by dissolving hemicellulose, lignin, and silica, by hydrolyzing uranic and acetic acid esters, and by swelling cellulose, decreasing its crystallinity. This increases the biodegradability of the cell walls due to cleavage of the bonds between lignin and hemicellulose or lignin and cellulose, allowing their preseparation $[7,8]$. On the other hand, in the paper industry, it has been demonstrated that the addition of hemicelluloses as additive in the cellulosic pulp can improve some mechanical properties of the paper, among other features of papermaking [9, 10].

This work details our research on the integral use of agro-industrial residues, aiming at an economic and environmental-friendly process, together with recommendations for

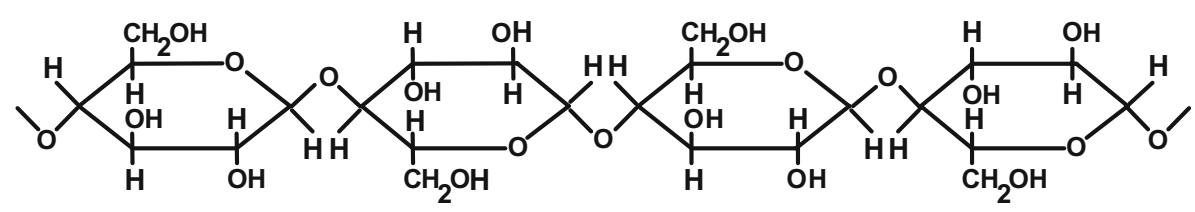

Fig. 1 Schematic illustration of the cellulose chain [5] 


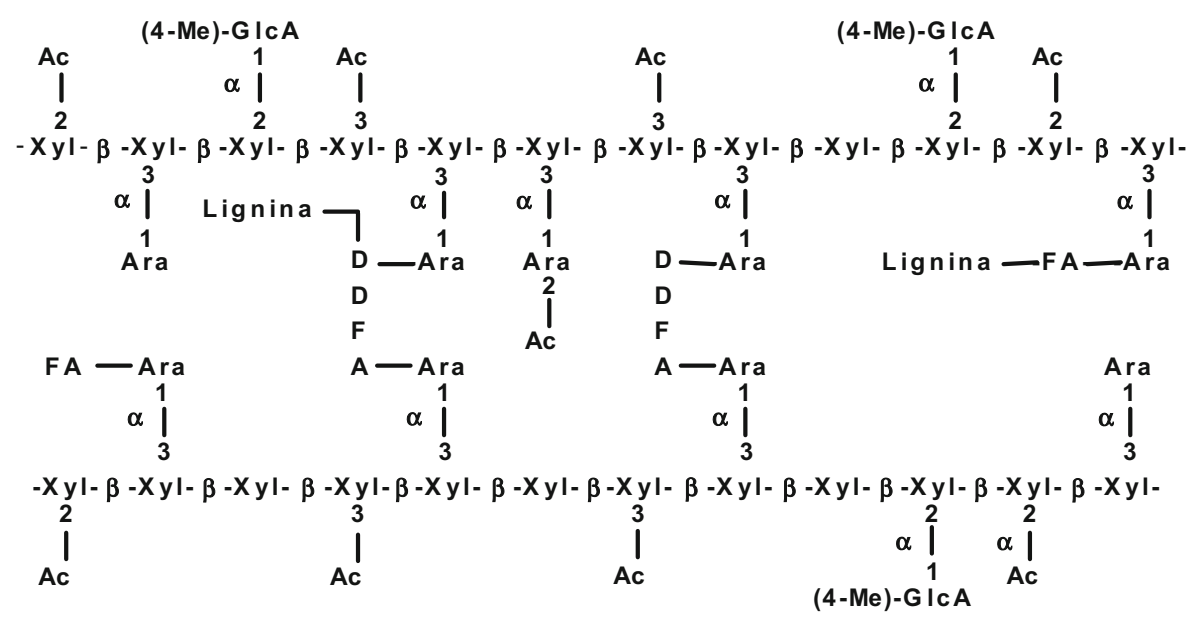

Fig. 2 Schematic illustration of xylans from Gramineae; $X y l$ 1,4-D-xylopiranose; Ara L-arabinofuranose; Ac acetyl; (4-Me)-GlcA (4-O-methyl)-D-glucopyranuronic acid; $F A$ ferulic acid; DDFA dehydroferulic [6]

hemicellulose extraction processes from wheat straw, in order to make possible the use of this hemicellulose as additive in the papermaking industry, always keeping in mind the use of the other lignocellulosic fractions (cellulose and lignin) in other applications. Properties of wheat straw hemicelluloses worth exploiting are their ability to serve as

Wheat Straw

(1) Dry at $50^{\circ} \mathrm{C}$ for $12 \mathrm{~h}$

(2) Determination of holocelulose

(3) Determination of $\alpha$-cellulose

Dried Wheat straw

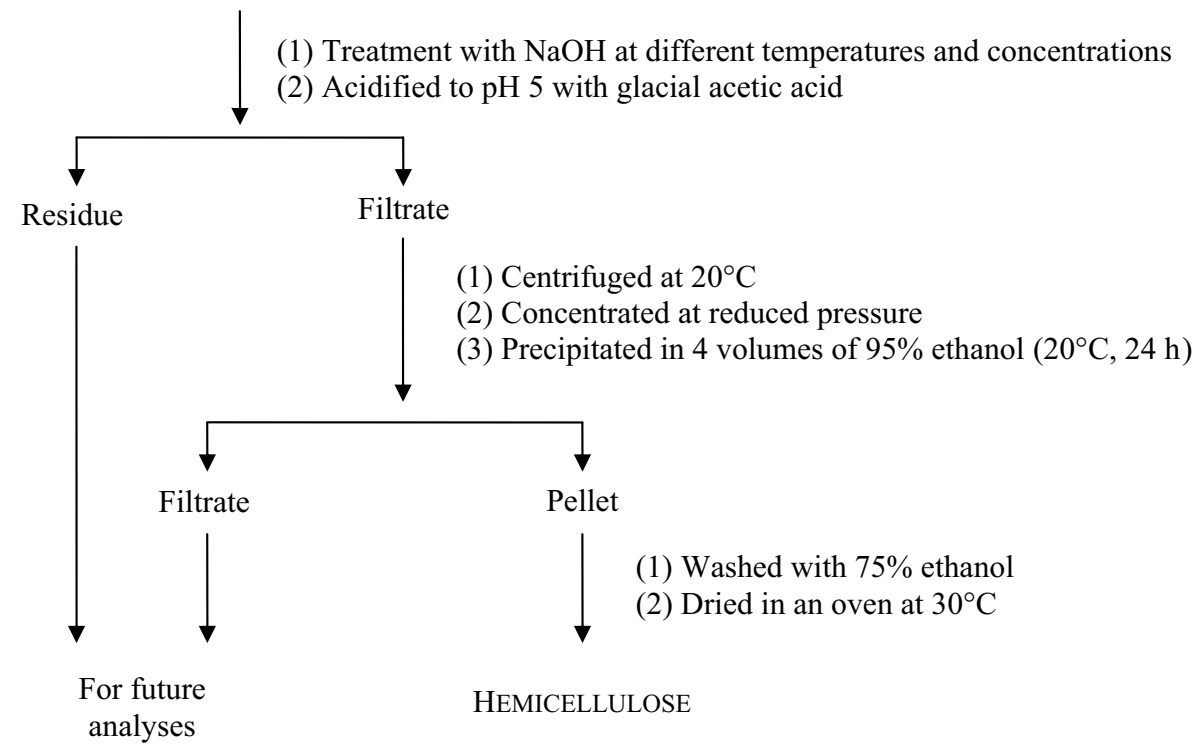

Fig. 3 Scheme for extraction of hemicelluloses from ground wheat straw 
adhesives, thickeners, and stabilisers, and as film formers and emulsifiers [11]. Thus, future applications of agro-industrial residues in bioprocesses provide alternative substrates, economic and environmental-friendly process, and help in solving environmental problems which their disposal could cause.

\section{Materials and Methods}

\section{Materials}

Wheat straw was kindly supplied by a local farmer (Portugal) of the variety Rendegobreadweack, which was harvest July 2006 and storage in dry pocked 6-7\% moisture; this material was not ensiled. After being dried at $50{ }^{\circ} \mathrm{C}$ in an oven for $12 \mathrm{~h}$, the straw was cut into small pieces $(1-3 \mathrm{~cm})$, milled in a knives mill to pass through a $0.9-\mathrm{mm}$ screen, and stored at room temperature. All chemicals used were of analytical or reagent grade. Experiments were performed in triplicate, and yields are given on a dry-weight (untreated straw) basis.

\section{Chemical Composition of Wheat Straw}

Approximately $2 \mathrm{~g}$ of ground wheat straw was treated with $10 \mathrm{ml}$ of $72 \% \mathrm{H}_{2} \mathrm{SO}_{4}$ with stirring at $45^{\circ} \mathrm{C}$ for $7 \mathrm{~min}$. The reaction was interrupted by adding $50 \mathrm{ml}$ of distilled water, and the mixture was then transferred to a 500-ml Erlenmeyer flask and the volume brought to $275 \mathrm{ml}$. The flask was autoclaved for $30 \mathrm{~min}$ at $121{ }^{\circ} \mathrm{C} / 1.05$ bar for the complete hydrolysis of oligomers. The mixture was filtered and the hydrolysate brought to $500 \mathrm{ml}$. After filtration through a Sep-Pak $\mathrm{C}_{18}$ cartridge to remove aromatic compounds, the hydrolysate was analyzed in a MetaCarb $67 \mathrm{H}$ column at $45{ }^{\circ} \mathrm{C}$ by using a Jasco chromatograph with refraction-index detector. The mobile phase was $0.005 \mathrm{~mol} / \mathrm{l} \mathrm{H}_{2} \mathrm{SO}_{4}$ at $0.6 \mathrm{ml} / \mathrm{min}$ flow rate. Sugar concentrations, reported as xylan and glucan, were determined from calibration curves of pure compounds. Lignin in the solid residue was determined by gravimetric analysis [12].

\section{Determination of Holocellulose}

Approximately 5-g samples of dry ground straw (with known moisture content) were transferred to $250-\mathrm{ml}$ Erlenmeyer flasks containing $160 \mathrm{ml}$ of distilled water, $0.5 \mathrm{ml}$ of acetic acid, and $1.5 \mathrm{~g}$ of sodium chlorite. The samples were heated for $60 \mathrm{~min}$ in a water bath at $70-80{ }^{\circ} \mathrm{C}$ with agitation every $10 \mathrm{~min}$. Then, $0.5 \mathrm{ml}$ of acetic acid and $1.5 \mathrm{~g}$ of sodium chlorite were added. This addition was repeated at 60 -min intervals for $4 \mathrm{~h}$ reaction time. After $4 \mathrm{~h}$, the Erlenmeyer flask was put in an ice bath and cooled to $10{ }^{\circ} \mathrm{C}$. The samples were subsequently filtered in crucibles of porosity 2 . The residue was washed with 1.61 of hot distilled water under vacuum. The samples were finally washed with acetone and dried at room temperature $[13,14]$.

\section{Determination of $\alpha$-Cellulose}

Approximately 1-g samples of holocellulose (with known water content) were transferred to $150-\mathrm{ml}$ beakers and put in water bath at $20{ }^{\circ} \mathrm{C}$. Then, $11.8 \mathrm{ml}$ of $17.5 \% \mathrm{NaOH}$ solution was added under stirring, $5 \mathrm{ml}$ being added in the first $1 \mathrm{~min}, 3.4 \mathrm{ml}$ in the next $45 \mathrm{~s}$, and $3.4 \mathrm{ml}$ 
in the next $15 \mathrm{~s}$. The samples were left at rest by $3 \mathrm{~min}$, and then $13.6 \mathrm{ml}$ of $17.5 \% \mathrm{NaOH}$ was added during $10 \mathrm{~min}(3.4 \mathrm{ml}$ initially with stirring, $3.4 \mathrm{ml}$ at minute $2.5,3.4 \mathrm{ml}$ at minute 5 , and $3.4 \mathrm{ml}$ at minute 7.5 ). Samples were covered and left at $20^{\circ} \mathrm{C}$ for $30 \mathrm{~min}$. Afterwards, $33.4 \mathrm{ml}$ of distilled water were added, and the mixture was left for another $30 \mathrm{~min}$ at $20^{\circ} \mathrm{C}$. The samples were filtered in a crucible of porosity 2, washed with $8 \mathrm{ml} \mathrm{of} 8.3 \% \mathrm{NaOH}$, and washed with $400 \mathrm{ml}$ of distilled water. The volume was completed with acetic acid $(50 \mathrm{ml})$ $2 \mathrm{~mol} / \mathrm{l}$ and left at rest for $3 \mathrm{~min}$. The samples were filtered to remove acetic acid, washed with 31 of distilled water at room temperature, and dried overnight $[13,14]$.

Extraction of Hemicellulose

A sample of $5 \mathrm{~g}$ dry ground straw was treated with $200 \mathrm{ml} \mathrm{NaOH}$ solution (concentrations of 0.25 and $0.50 \mathrm{~mol} / \mathrm{l}$ ) for $2 \mathrm{~h}$ at different temperatures $\left(30\right.$ and $\left.55^{\circ} \mathrm{C}\right)$. After the indicated period of treatment, the sample was acidified to $\mathrm{pH} 5$ with glacial acetic acid, concentrated to about $30 \mathrm{ml}$ under reduced pressure, and then filtered. The alkali-soluble hemicelluloses were then precipitated by pouring the concentrated supernatant fluid with four volumes of $95 \%$ ethanol $\left(20^{\circ} \mathrm{C}, 24 \mathrm{~h}\right)$. The precipitates were recovered by filtration, washed with $70 \%$ ethanol, and air dried. The scheme for fractionation of hemicelluloses from wheat straw is illustrated in Fig. 3.

\section{Chemical Composition of Extracted Hemicellulose of Wheat Straw}

Samples of $0.3 \mathrm{~g}$ of dry hemicellulose were treated with $3 \mathrm{ml}$ of $72 \% \mathrm{H}_{2} \mathrm{SO}_{4}$ under stirring at $30{ }^{\circ} \mathrm{C}$ for $1 \mathrm{~h}$. The reaction was interrupted by adding $79 \mathrm{ml}$ of distilled water, and the mixture was then transferred to a 250-ml Erlenmeyer flask. The flask was autoclaved for $1 \mathrm{~h}$ at 1.25 bar for the complete hydrolysis of oligomers. The mixture was filtered and the hydrolysate brought to $250 \mathrm{ml}$. After filtration through a Sep-Pak C18 cartridge to remove aromatic compounds, the hydrolysate was analyzed in a MetaCarb $67 \mathrm{H}$ at $45{ }^{\circ} \mathrm{C}$ by using a Jasco chromatograph with refraction-index detector. The mobile phase was $0.005 \mathrm{~mol} /$ $1 \mathrm{H}_{2} \mathrm{SO}_{4}$ at $0.6 \mathrm{ml} / \mathrm{min}$ flow rate. Sugar concentrations, reported as xylan and glucan, were determined from calibration curves of pure compounds. Lignin was determined by gravimetric analysis [15].

\section{Fourier Transform Infrared of Samples}

Fourier transform infrared of samples (FTIR) spectra were obtained on a Fourier Transform Infrared Spectrophotometer (Bomem MB Series) operating at $4 \mathrm{~cm}^{-1}$ resolutions and using a $\mathrm{KBr}$ disc containing $1 \%$ finely ground samples.

\section{Thermogravimetric Analyzer}

Thermal stability of hemicelluloses was performed using thermogravimetric analysis (TGA) on a thermal analyzer (TA Instruments High-Resolution Model Q-500). The apparatus was continually flushed with nitrogen. The samples weighed between 10 and $13 \mathrm{mg}$ and were run from room temperature to $600{ }^{\circ} \mathrm{C}$ at a rate of $10{ }^{\circ} \mathrm{C} / \mathrm{min}$.

\section{Scanning Electron Microscopy}

The samples were mounted on stubs, freeze dried, coated with gold, examined, and photographed in a Scanning Electron Microscope LEICA S 360. 


\section{Results and Discussion}

In wheat straw, cellulose and hemicelluloses are the predominant components and comprise about $70 \%$ of the dry weight. The third major cell-wall component in straw is lignin. However, to determine the overall efficiency of any process of extraction or process designed to convert lignocellulosic polysaccharides to value-added products, it is first necessary to determine the composition of these lignocellulosic components. In this work, the sulfuric-acid-based method was used for this purpose, as it is one of the standard methods referenced in the literature. The composition of the wheat straw used is given in Table 1. These data were in good agreement with those presented in other works [16].

The fraction consisting of cellulose and hemicellulose or, in other words, the set of all carbohydrates in a lignocellulosic material, is also called holocellulose. Thus, holocellulose is the product obtained after selective removal of lignin, with very low residual-lignin content, minimal loss of polysaccharide, and minimal oxidative and hydrolytic degradation of cellulose. The $\alpha$-cellulose is the part of material that is insoluble in strong $\mathrm{NaOH}$ $(17.5 \%)$ and may also be designated by crystalline cellulose [5]. In this work, the values of holocellulose and $\alpha$-cellulose are also shown in Table 1.

Extraction of hemicelluloses under alkaline conditions involves alkaline hydrolysis of ester linkages to liberate them from the lignocellulosic matrix followed by extraction in an aqueous medium. However, the liberation of the hemicellulosic component from the plant cell walls is restricted by the presence of lignin network as well as ester and ether ligninhemicellulose linkages [17]. As can be seen from Table 2, the treatment of wheat straw solely with water and 0.25 and $0.50 \mathrm{~mol} / 1 \mathrm{NaOH}$ at 30 and $55^{\circ} \mathrm{C}$ for $2 \mathrm{~h}$ released $1.9,8.2$, $13.3,2.3,15.7$, and $17.3 \%$ hemicelluloses (\% dry starting material), corresponding to the dissolution of $5.4,23.3,37.9,6.6,44.7$, and $49.3 \%$ of the original hemicelluloses, respectively. This calculation, which was used to convert the percent extracted hemicelluloses, was yield $(\%) /$ hemicellulose total $(\%)$. Thus, these results revealed that the extraction of the wheat straw was effective and that the highest extraction yield was obtained with $0.50 \mathrm{~mol} / 1 \mathrm{NaOH}$ (49.3\% of the total available hemicelluloses). Apparently, a part of the hemicelluloses is attached within the cell walls (the more acidic and branched fraction), while the major part of the hemicelluloses (the more linear and less acidic fraction) is embedded firmly in the cell wall [5]. It can be speculated that this difference in extractability of the hemicelluloses is a result of a different function/location of these polysaccharides in the cell wall.

Table 1 Chemical composition of the wheat straw.

\begin{tabular}{ll}
\hline Chemical components & Composition (\%) \\
\hline Glucan & $36.7 \pm 0.6$ \\
Hemicelluloses & $35.1 \pm 1.1$ \\
Xylan & $32.6 \pm 1.1$ \\
Acetyl group & $2.4 \pm 0.1$ \\
Total lignin & $26.7 \pm 0.1$ \\
Soluble lignin & $7.1 \pm 0.1$ \\
Klason lignin & $19.6 \pm 0.1$ \\
Ash & $1.3 \pm 0.3$ \\
Total chemical composition & $99.8 \pm 0.5$ \\
Holocellulose & $72.2 \pm 0.1$ \\
$\alpha$-cellulose & $51.5 \pm 1.1$ \\
\hline
\end{tabular}


Table 2 The yield and monosaccharide constituent of hemicelluloses (\% dry matter).

\begin{tabular}{|c|c|c|c|c|c|c|c|}
\hline \multirow[t]{4}{*}{ Yield and constituents (\%) } & \multirow[t]{4}{*}{ Birch wood } & \multicolumn{6}{|c|}{ Wheat straw } \\
\hline & & \multicolumn{3}{|c|}{ Temperature $\left(30^{\circ} \mathrm{C}\right)$} & \multicolumn{3}{|c|}{ Temperature $\left(55^{\circ} \mathrm{C}\right)$} \\
\hline & & \multicolumn{3}{|c|}{ Concentration $\mathrm{NaOH}(\mathrm{mol} / \mathrm{l})$} & \multicolumn{3}{|c|}{ Concentration $\mathrm{NaOH}(\mathrm{mol} / \mathrm{l})$} \\
\hline & & 0.0 & 0.25 & 0.50 & 0.0 & 0.25 & 0.50 \\
\hline Yield & - & $1.9 \pm 0.3$ & $8.2 \pm 0.5$ & $13.3 \pm 0.6$ & $2.3 \pm 0.2$ & $15.7 \pm 0.3$ & $17.3 \pm 0.4$ \\
\hline Xylan & 48.1 & 0 & $13.2 \pm 0.2$ & $17.8 \pm 0.5$ & 0 & $11.6 \pm 0.3$ & $17.6 \pm 0.4$ \\
\hline Arabinan & 0 & 0 & $26.5 \pm 0.3$ & $24.9 \pm 0.5$ & 0 & $20.2 \pm 0.3$ & $36.5 \pm 0.4$ \\
\hline Acetyl group & 6.9 & 0 & $2.4 \pm 0.1$ & $2.4 \pm 0.1$ & 0 & $2.4 \pm 0.1$ & $2.4 \pm 0.1$ \\
\hline
\end{tabular}

Alkaline solubilization of hemicelluloses is usually mentioned as responsible for the disruption and breakage of hydrogen bonds. In addition, all these ester-linked substituents of the hemicellulose and other cell-wall components can be cleaved by alkali [18]. This tends to increase hydrophilicity and hence solubility of the material.

However, to characterize the solubilized hemicelluloses of the wheat-straw samples, the four extracted fractions obtained and the commercial hemicellulose of birch wood (Sigma $\left.{ }^{\circledR}\right)$ were hydrolyzed to determine their sugar constituents, and the results are given in Table 2. The major monosaccharide obtained was xylose of birch wood $(48.1 \%)$, indicating the presence of a xylan. In the hemicelluloses of wheat straw, the major monosaccharide was arabinose $(36.5 \%)$, indicating the presence of an arabinoxylan. However, these sugar concentrations were very low; which can likely be due to the methodology used to determined the chemical composition of the hemicellulose extracted from wheat straw.

Infrared spectroscopy is an effective way to identify the presence of certain functional groups in a molecule. Also, one can use the unique collection of absorption bands to confirm the identity of a pure compound or to detect the presence of specific impurities [19, 20]. The FTIR spectra of wheat straw and pretreated wheat straws (Fig. 4) initially appeared rather similar. However, in a closer examination, spectra of pretreated wheat straw with water (lines 2 and 3) were similar to those of untreated wheat straw (line 1), and spectra of $\mathrm{NaOH}$ pretreated wheat straw (lines 4-7) can be clearly distinguished from those of untreated wheat straw (line 1) by the disappearance of ester linkage absorption $\left(1,733 \mathrm{~cm}^{-1}\right.$ band).

The $1,653 \mathrm{~cm}^{-1}$ band is also a carbonyl stretching band due to para-substituted ketones or aryl aldehydes, which has the same absorbance among the seven FTIR spectra. The absorption ratios of the $1,250 \mathrm{~cm}^{-1}$ band (guaiacyl units) and the $1,321 \mathrm{~cm}^{-1}$ band (syringyl units) to $1,500 \mathrm{~cm}^{-1}$ band are similar for the four pretreated wheat straw samples (lines 4-7, Fig. 4) indicating high syringyl content (weak absorption at $1,250 \mathrm{~cm}^{-1}$ ).

In the untreated straw sample (line 1, Fig. 2), the intensity of the $1,250 \mathrm{~cm}^{-1}$ band was much higher than that in $\mathrm{NaOH}$ pretreated straw (lines 4-7, Fig. 4), suggesting a relatively higher guaiacyl content in the original wheat straw. The broad band between 3,600 and $3,000 \mathrm{~cm}^{-1}$, corresponding to vibrations of the hydroxyl groups, appeared to be similar in all spectra. Methyl, methylene, and methine group vibrations appeared at the $2,918 \mathrm{~cm}^{-1}$ band and were present in all straw spectra. The strong bands in the $1,157-892 \mathrm{~cm}^{-1}$ region can be attributed to the polysaccharides present in the wheat straw or pretreated wheat straw. It was also noted that the band at $1,053 \mathrm{~cm}^{-1}$, which might be assigned to primary hydroxyl vibration, appeared in all the straw spectra.

The FTIR spectra of hemicelluloses extracted from birch wood (commercial xylan, line 1) and wheat straw hemicellulose extracted with $0.25 \mathrm{~mol} / \mathrm{l} \mathrm{NaOH} / 30{ }^{\circ} \mathrm{C}$ (line 2), 


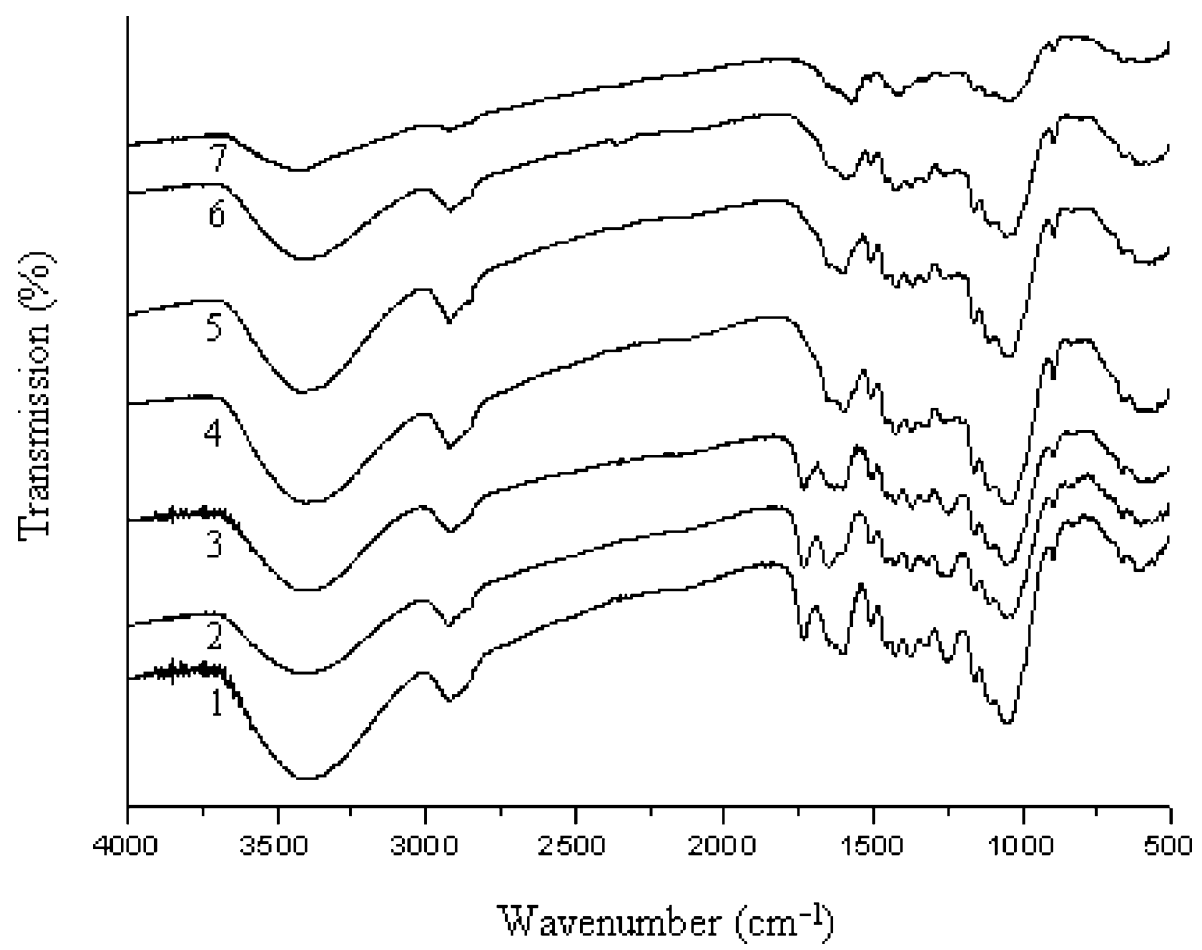

Fig. 4 FTIR spectra of untreated wheat straw (line 1), pretreated wheat straw with only water at $30{ }^{\circ} \mathrm{C}$ (line 2) and $55{ }^{\circ} \mathrm{C}$ (line 3), and pretreated wheat straw with $0.25 \mathrm{~mol} / 1 \mathrm{NaOH} / 30{ }^{\circ} \mathrm{C}$ (line 4 ), $0.50 \mathrm{~mol} / 1 \mathrm{NaOH} /$ $30{ }^{\circ} \mathrm{C}$ (line 5), $0.25 \mathrm{~mol} / 1 \mathrm{NaOH} / 55^{\circ} \mathrm{C}$ (line 6), and $0.50 \mathrm{~mol} / 1 \mathrm{NaOH} / 55^{\circ} \mathrm{C}$ (line 7); all the treatments for $2 \mathrm{~h}$

$0.50 \mathrm{~mol} / 1 \mathrm{NaOH} / 30{ }^{\circ} \mathrm{C}$ (line 3), $0.25 \mathrm{~mol} / 1 \mathrm{NaOH} / 55^{\circ} \mathrm{C}$ (line 4), and $0.50 \mathrm{~mol} / 1 \mathrm{NaOH} /$ $55^{\circ} \mathrm{C}$ (line 5) are illustrated in Fig. 5. As can be seen, the five spectral profiles and relative intensities of the bands were rather similar, indicating similar structures between the hemicelluloses. Similar features appeared in the spectra of lines 2-5 (Fig. 5), indicating analogous structures between the alkali-soluble hemicellulosic preparations.

The analysis of FTIR data showed that all hemicellulosic fractions clearly displayed the typical signal pattern for the hemicellulosic fraction and had a specific band maximum in the $1,200-1,000 \mathrm{~cm}^{-1}$ region. The absorption at $1,600 \mathrm{~cm}^{-1}$, shown in all spectra is mainly associated with absorbed water [21]. Bands between 1,166 and $1,000 \mathrm{~cm}^{-1}$ are typical of xylans. The presence of the arabinosyl side chains is documented by the two low-intensity shoulders at 1,166 and $986 \mathrm{~cm}^{-1}$.

As expected, the absence of a signal around $1,720 \mathrm{~cm}^{-1}$ for carbonyl stretching in all the four spectra indicated that the treatment with alkali under the conditions given did not significantly attack the glycosidic linkages and hydroxyl groups of hemicelluloses. The prominent band around $3,443 \mathrm{~cm}^{-1}$ represents the hydroxyl stretching vibrations of the hemicelluloses and water involved in hydrogen bonding. The absorbances at 3,422, 2,927, $1,468,1,421,1,388,1,251,1,166,1,085,1,049,986$, and $897 \mathrm{~cm}^{-1}$ in the spectra are associated with hemicelluloses. The lignin-related absorbance at $1,509 \mathrm{~cm}^{-1}$ is rather weak and poorly resolved, reflecting the low level of associated lignin in the hemicelluloses.

The prominent band at $1,046 \mathrm{~cm}^{-1}$ is attributed to the $\mathrm{C}-\mathrm{O}, \mathrm{C}-\mathrm{C}$ stretching or $\mathrm{C}-\mathrm{OH}$ bending in hemicelluloses [22]. The band at $897 \mathrm{~cm}^{-1}$, which corresponds to the $\mathrm{C} 1$ group 


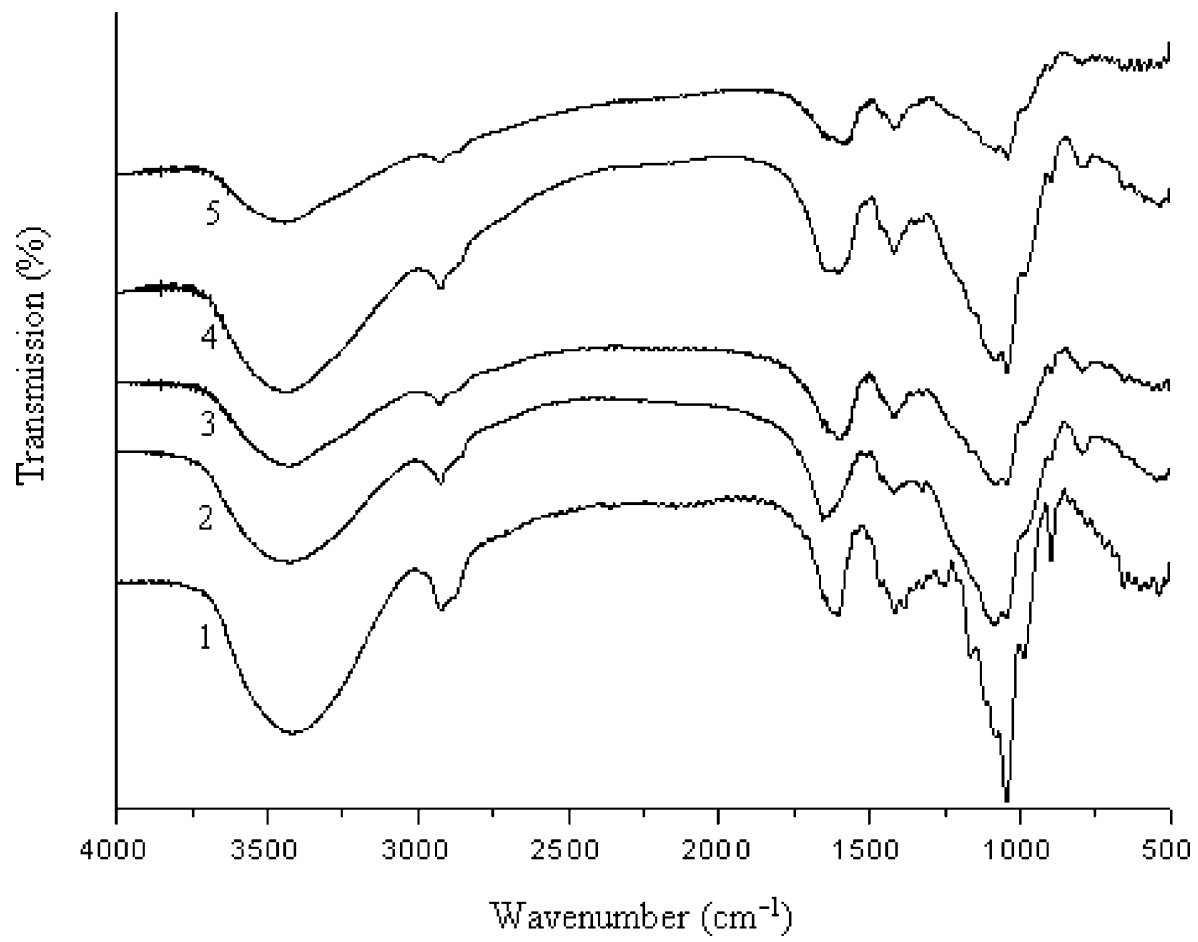

Fig. 5 FTIR spectra of commercial xylan from birch wood (line 1) and FTIR spectra of wheat straw hemicellulose extracted with $0.25 \mathrm{~mol} / 1 \mathrm{NaOH} / 30{ }^{\circ} \mathrm{C}$ (line 2), $0.50 \mathrm{~mol} / 1 \mathrm{NaOH} / 30{ }^{\circ} \mathrm{C}$ (line 3 ), $0.25 \mathrm{~mol} /$ $1 \mathrm{NaOH} / 55^{\circ} \mathrm{C}$ (line 4), and $0.50 \mathrm{~mol} / 1 \mathrm{NaOH} / 55^{\circ} \mathrm{C}$ (line 5); all the treatments for $2 \mathrm{~h}$

frequency or ring frequency, is characteristic of beta-glycosidic linkages between the sugar units [23]. The presence of the arabinosyl side chains is identified by the low-intensity shoulder at $1,164 \mathrm{~cm}^{-1}$, corresponding to the $\mathrm{C}-\mathrm{O}-\mathrm{C}$ vibration in hemicelluloses. The typical values of xylan in the spectra indicated that alkaline extraction treatment under the conditions used did not result in any significant change in the macromolecular structure of hemicelluloses.

TGA measures changes in weight of a sample with increasing temperature. Moisture content and presence of volatile species can be determined with this technique. In this work, the thermal properties (Fig. 6) of a commercial xylan from birch wood (line 1), wheat straw (line 2), hemicellulosic preparations after treatment with $0.50 \mathrm{~mol} / 1 \mathrm{NaOH} / 55^{\circ} \mathrm{C}$ (line 3), $0.50 \mathrm{~mol} / 1 \mathrm{NaOH} / 30{ }^{\circ} \mathrm{C}$ (line 4), $0.25 \mathrm{~mol} / 1 \mathrm{NaOH} / 55^{\circ} \mathrm{C}$ (line 5), and $0.25 \mathrm{~mol} / 1 \mathrm{NaOH} /$ $30{ }^{\circ} \mathrm{C}$ (line 6) for $2 \mathrm{~h}$ were studied by TGA. All these samples were found to be initially degraded at about $200{ }^{\circ} \mathrm{C}$, and their maximum rates of weight loss were observed between 220 and $320^{\circ} \mathrm{C}$, except for the wheat straw sample (sample 2 in Fig. 6), with its maximum rate of weight loss observed between about 220 and $350^{\circ} \mathrm{C}$. As observed, the commercial xylan sample from birch wood and the wheat straw sample were stable up to $190{ }^{\circ} \mathrm{C}$ (lines 1 and 2, respectively), and the hemicellulosic preparations after treatment were stable up to $220^{\circ} \mathrm{C}$ (lines 3, 4, 5, and 6, respectively). Beyond these temperatures, thermal degradation takes place. As can be seen (Fig. 6), at 30\% weight loss, the decomposition temperatures of the degraded samples occurred at $270{ }^{\circ} \mathrm{C}$ (lines 1 and 3), $280{ }^{\circ} \mathrm{C}$ (lines 4 and 5), and $294{ }^{\circ} \mathrm{C}$ (lines 3 and 6). When scanning electron microscopy was used (Fig. 7), the fiber surface of 


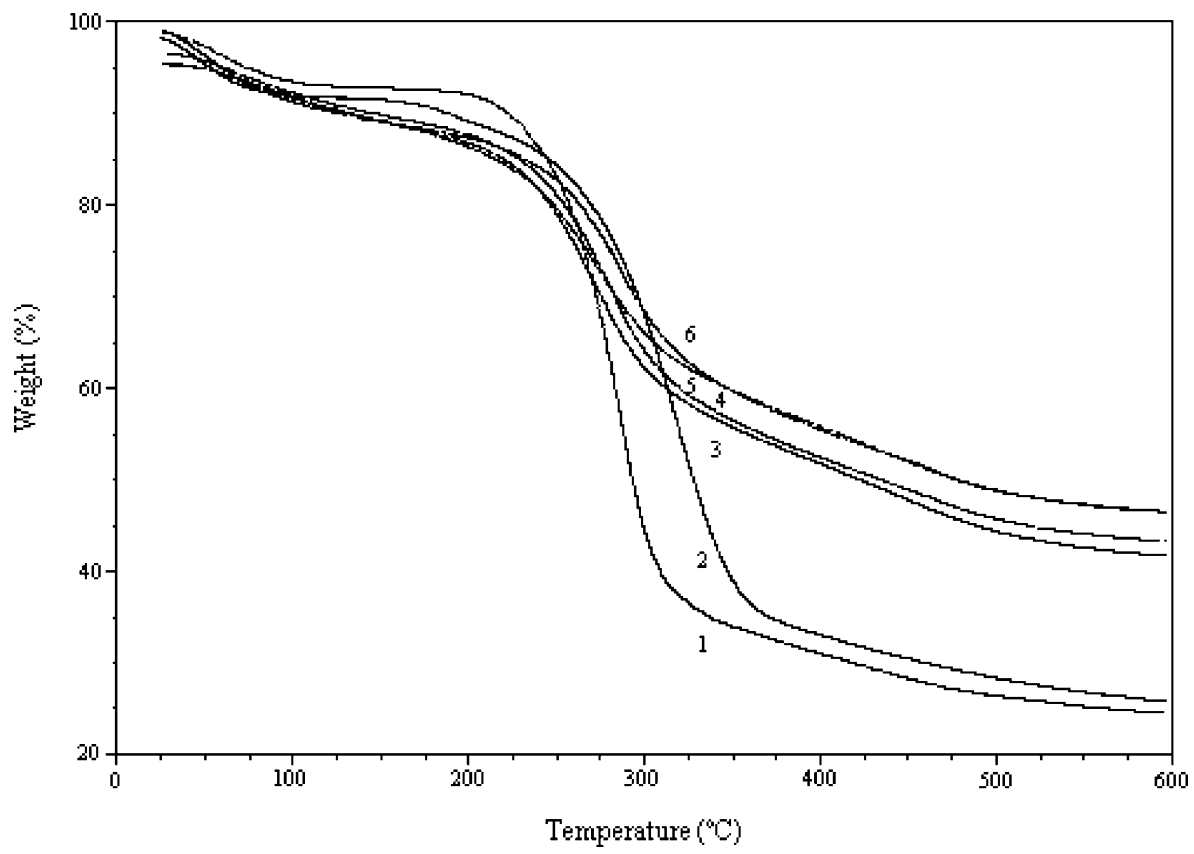

Fig. 6 TGA curves of commercial xylan from birch wood (line 1), wheat straw (line 2), and hemicellulosic preparations after treatment with $0.50 \mathrm{~mol} / 1 \mathrm{NaOH} / 55^{\circ} \mathrm{C}$ (line 3), $0.50 \mathrm{~mol} / 1 \mathrm{NaOH} / 30{ }^{\circ} \mathrm{C}$ (line 4 ), $0.25 \mathrm{~mol} /$ $1 \mathrm{NaOH} / 55^{\circ} \mathrm{C}$ (line 5), and $0.25 \mathrm{~mol} / 1 \mathrm{NaOH} / 30{ }^{\circ} \mathrm{C}$ (line 6) for $2 \mathrm{~h}$

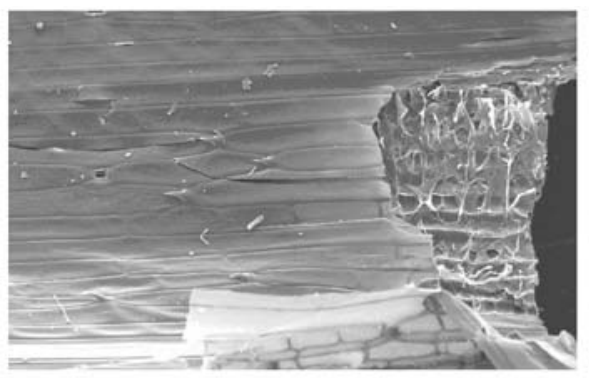

a

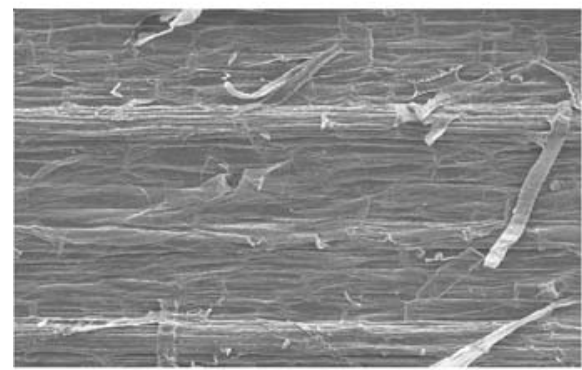

b

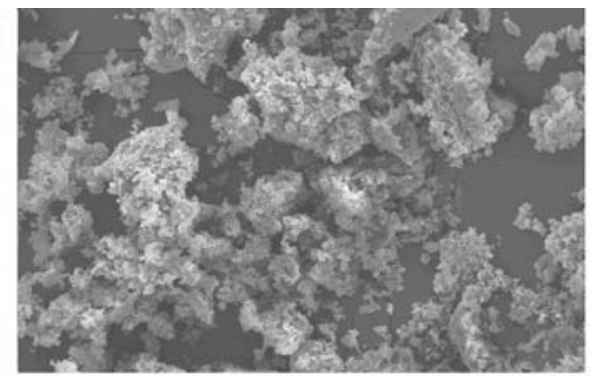

C

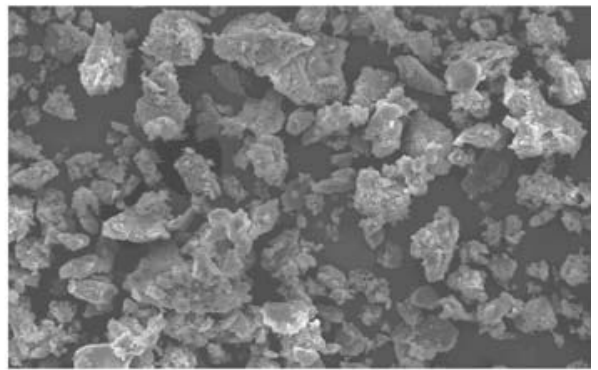

d

Fig. 7 Scanning electron microscopy of a wheat straw (magnification, $\times 150$ ); $\mathbf{b}$ wheat straw treated with $0.25 \mathrm{~mol} / 1 \mathrm{NaOH}$ (magnification, $\times 150$ ); $\mathbf{c}$ extracted hemicellulose of birch wood (magnification, $\times 500$ ); $\mathbf{d}$ extracted hemicellulose of wheat straw (magnification, $\times 500$ ) 
wheat straw clearly shows the modifications resulting from the NAOH action on the fiber structure (A and B). Wheat-straw hemicellulose (C) showed the similar appearance of the birch-wood hemicellulose (D) but with increased rugosity.

\section{Conclusions}

Hemicellulose could be extracted from wheat straw in a single stage using alkaline extraction process $(0.50 \mathrm{~mol} / \mathrm{l} \mathrm{NaOH})$ at $55{ }^{\circ} \mathrm{C}$ for $2 \mathrm{~h}$, obtaining $17.3 \%$ of yield on dry base, corresponding to the dissolution of $49.3 \%$ of the original hemicellulose. Although being a preliminary study, these results suggest the potential of this process to hemicellulose extraction, making possible its biotechnological applications. The obtained material was identified as arabinoxylan by chemical analysis and characterized by FTIR spectroscopy and TGA. The analysis of FTIR (FTIR scans) showed typical signal pattern for the hemicellulosic factions. Microscopic evaluation shows some differences in the behavior of the hemicellulose when compared with birch-wood xylan.

This procedure shows potential to be employed as a part of a process leading to the integral use of lignocellulosic materials in different biotechnological processes. Thus, these future applications of agro-industrial residues in bioprocesses on the one hand provide alternative substrates and on the other hand help in solving environmental problems which their disposal could cause. Furthermore, many publications refer to the fact that the utilization of both cellulose and hemicellulosic sugars present in typical lignocellulosic biomass hydrolyzates is essential for the economical production, e.g., of bio-ethanol. However, the integral use not only of a hemicellulose fraction but also of the lignin can help in this concept of economical production of different products.

Acknowledgements The authors acknowledge the financial support from FCT (Fundação para a Ciência e Tecnologia/Portugal, SFRH/BPD/26156/2005 and SFRH/BPD/26108/2005), as well as from FAPESP (Fundação de Amparo a Pesquisa do Estado de São Paulo/Brazil) and CNPq (Conselho Nacional de Desenvolvimento Científico e Tecnológico).

\section{References}

1. Gonçalves, A. R., Benar, P., Costa, S. M., Ruzene, D. S., Moriya, R. Y., \& Luz, S. M., et al. (2005). Applied Biochemistry and Biotechnology, 121, 821-826.

2. Küçük, M. M., \& Demirbas, A. (1997). Energy Conversion Management, 38(2), 151-165.

3. Sun, Y., \& Cheng, J. (2002). Bioresource Technology, 83, 1-11.

4. Montane, D., Farriol, X., Salvado, J., Jollez, P., \& Chornet, E. (1998). Journal of Wood Chemistry and Technology, 18, 171.

5. Fengel, D., \& Wegener, G. (1989). Wood chemistry, ultrastructure, reactions p. (p. 613). Berlin: Walter de Gruyter.

6. McDougall, G. J., Morrison, I. M., Stewart, D., Weyers, J. D. B., \& Hillman, J. R. J. (1993). Science of Food and Agriculture, 621-20.

7. Jackson, M. G. (1977). Animal Feed Science and Technology, 2, 105-130.

8. Spencer, R. R., \& Akin, D. E. (1980). Journal of Animal Science, 51(5), 1189-1196.

9. Lima, D. U., Oliveira, R. C., \& Buckeridge, M. S. (2003). Carbohydrate Polymers, 52, 367-373.

10. Saake, B., Busse, T., \& Puls, J. (2005). Appita, 2, 141-146.

11. Doner, L. W., \& Hicks, K. (1997). Cereal Chemistry, 74, 176.

12. Rocha, G. J. M. (2000). PhD thesis, São Carlos/Universidade de São Paulo, Brazil,

13. Browing, B. L. (1963). The chemistry of wood p. (p. 574). New York: Interscience.

14. Ruzene, D. S., Gonçalves, A. R., Teixeira, J. A., \& Pessoa De Amorim, M. T. (2007). Animal Feed Science and Technology, 136-140. 
15. Ferraz, A., Rodriguez, J., Freer, J., \& Baeza, J. (2000). Bioresource Technology, 74, 201-212.

16. Wilkie, K. C. B. (1979). Advances in Carbohydrate Chemistry and Biochemistry, 36, 215-264.

17. Ebringerová, A., \& Heinze, T. (2000). Macromolecular rapid communications, 21, 542-556.

18. Ternrud, I. (1987). Degradation of untreated and alkalitreated straw polysaccharides in ruminants. Uppsala: The Swedish University of Agricultural Sciences.

19. Faix, O. (1991). Holzforschung, 45, 21-27.

20. Gonçalves, A. R., \& Ruzene, D. S. (2001). Applied Biochemistry and Biotechnology, 91-93, 63-70.

21. Kacurakova, M., Belton, P. S., Wilson, R. H., Hirsch, J., \& Ebringerova, A. (1998). Journal of the Science of Food and Agriculture, 77, 38-44.

22. Kacurakora, M., Ebringerova, A., Hirsch, J., \& Hromadkova, Z. (1994). Journal of the Science of Food and Agriculture, 66, 423.

23. Gupta, S., Madan, R. N., \& Bansal, M. C. (1987). Tappi Journal, 70, 113-114. 